\title{
ASO Author Reflections: Is It Truly Necessary to Resect the Thoracic Duct in Esophagectomy for Esophageal Cancer?
}

\author{
Taro Oshikiri, $\mathrm{MD}^{\mathbf{1}}$, and Yoshihiro Kakeji, $\mathrm{MD}^{\mathbf{1}}$ \\ Division of Gastrointestinal Surgery, Department of Surgery, Graduate School of Medicine, Kobe University, Kobe, \\ Hyogo, Japan
}

\section{PAST}

Thoracic duct (TD) resection has been recommended to harvest mediastinal lymph nodes (LNs) in the adipose tissue surrounding the TD. ${ }^{1}$ However, whether TD resection truly contributes to improve the prognosis of esophageal cancer patients is controversial. ${ }^{2}$ This clinical question was the rational for the conduct of our research. ${ }^{3}$

\section{PRESENT}

Our results ${ }^{3}$ showed that there were no significant differences in prognosis between the TD- resected and TDpreserved groups. In particular, in advanced stage cancers, the same result was confirmed. Moreover, the complication rate relating to TD resection was higher in the TD-resected group. Our study is novel and valuable because there have been no reports regarding the influence of TD resection on the prognosis of esophageal cancer patients.

ASO Author Reflections is a brief invited commentary on the article, "Thoracic Duct Resection during Esophagectomy Does Not Contribute to Improved Prognosis in Esophageal Squamous Cell Carcinoma: A Propensity Score Matched-Cohort Study", Ann Surg Oncol. 2019;26:4053-4061.

(C) Society of Surgical Oncology 2019

First Received: 11 October 2019;

Published Online: 28 October 2019

T. Oshikiri, MD

e-mail: oshikiri@med.kobe-u.ac.jp

\section{FUTURE}

As a result of these research results, we believe that uniform TD resection should be avoided in esophagectomy for patients with esophageal cancer. Moreover, we further recommend that additional research be conducted in the future regarding which patient characteristics are associated with a requirement for TD resection in this patient population.

DISCLOSURES Taro Oshikiri and Yoshihiro Kakeji have no conflicts of interest to disclose.

\section{REFERENCES}

1. Udagawa $\mathrm{H}$, Ueno $\mathrm{M}$, Shinohara $\mathrm{H}$, Haruta $\mathrm{S}$, Lee $\mathrm{S}$, Momose $\mathrm{K}$, et al. Shoud lymph nodes along the thoracic duct be dissected routinely in radical esophagectomy? Esophagus. 2014;11:204-10.

2. Matsuda S, Takeuchi H, Kawakubo H, et al. Clinical outcome of transthoracic esophagectomy with thoracic duct resection: number of dissected lymph node and distribution of lymph node metastasis around the thoracic duct. Medicine (Baltimore). 2016;95:e3839.

3. Oshikiri T, Takiguchi G, Miura S, et al. Thoracic duct resection during esophagectomy does not contribute to improved prognosis in esophageal squamous cell carcinoma: a propensity score matched-cohort study. Ann Surg Oncol. 2019;26:4053-61.

Publisher's Note Springer Nature remains neutral with regard to jurisdictional claims in published maps and institutional affiliations. 